\title{
Customer Boards as Vehicles of Change in Enterprise Software User Experience
}

\author{
Anna M. Wichansky \\ Oracle USA, 500 Oracle Parkway, MS2op2, Redwood Shores, California 94065 USA \\ Anna.Wichansky@oracle.com
}

\begin{abstract}
Traditional user-centered design processes do not leverage long-term customer-vendor relationships as a means of improving product usability. While designing a next-generation applications software suite, Oracle reached out to its most-involved customers for creative solutions to common user-experience issues. The mission of the Oracle Usability Advisory Board was to take enterprise software to a whole new level in usability. The board consisted of executives and senior managers primarily in information technology positions in different types of organizations. The board identified three major areas where it wanted to improve usability: consistency and design, integration and performance, and Web 2.0. Through various working groups, the board has developed tools for obtaining customer feedback on product usability, online seminars on technical topics, and outreach mechanisms to other customers. The board has effectively become Oracle's partner in ensuring product understanding and use, thus setting the stage for improved usability in the next-generation product.
\end{abstract}

Keywords: customer boards, enterprise software, user experience.

\section{Introduction}

To improve product usability, major enterprise software vendors have interacted with customers to obtain information on customer work processes as input to task flow modeling, and to get user feedback on prototypes of products under development. This type of user-centered design process generally involves end users in the target product market as participants in vendor ethnographic research, focus groups, surveys, and usability testing studies.

The methods in the user-centered design cycle are fairly labor intensive. A relatively small number of end users are often observed one at a time, various parameters of productivity and acceptance are measured in usability lab studies, and generalizations are made about how the users think and act in the course of work. Agile methods have speeded up this process, largely by using a minimalist approach [1].

In reality, how enterprise users work and what software they use is heavily influenced, if not largely determined, by purchase decision makers in their information technology (IT) departments. IT departments provide base image software installed on worker computers. This software is heavily customized and configured for the jobs that users are doing. Document and Web templates exist and are used throughout the organization. These templates dictate the content and appearance of deliverables, promote corporate consistency, and improve department productivity. 
So why aren't usability experts talking to IT departments and other corporate decision makers about usability, productivity, and process roadblocks in modern enterprise software? In most enterprises, these entities have real control over end user work processes and software.

Previous attempts to reach out to customers on behalf of usability efforts have been reported. Some good examples were the User Partnership Program at Siebel Systems and the Global Design Partners at Oracle [2]. These programs provided vendors with access to customers for three basic purposes: test recruiting, customer site visits (ethnographic style research), and verbal feedback about existing products. The goal of these programs was primarily to access end users (rather than decision makers). The author concludes that positive relationships are important for repeat sales; however, he does not detail exactly how this happens.

At the end of 2007, the Oracle Applications User Experience (UX) department was completing the design phase of an integrated suite of next-generation enterprise applications software. UX had flourished and grown at Oracle since 1994, when the first department and labs were founded. Numerous customers were tested-all of whom were in the participant database and some of whom had prior contacts in the department. It was time to access these long-term relationships with our most involved customers in a systematic way, not only to promote our new product, but also to educate customers about included Web-based technologies. Oracle wanted to see if customers expected new usability issues to crop up with the next-generation products, and if so, we wanted to address these issues early in development. These types of dialogues were necessary not only with end users but also with decision makers.

The Applications UX department sought to establish a new way of tapping into customer experience to drive usability a quantum level higher in future generations of software. The department encouraged open communication of experiences with its customers as a means of accessing customer strengths and problem-solving abilities at an executive level. The goal: maximize the usability of enterprise software in an atmosphere of mutual trust. The department also considered enlisting consultants, usability experts, and industry partners to facilitate, educate, and otherwise contribute as needed to reach solutions.

\section{Founding of the Oracle Usability Advisory Board}

Late in 2007, the Oracle Usability Advisory Board was formed to identify and address enterprise software usability issues in current and future products. This approach was intended to deal with usability on a macro level to determine and influence industry trends. The board reviewed and provided feedback on future technologies, shared best practices, and developed use cases, industry guidelines, standards, and requirements. The ultimate goal was to bring enterprise software usability to a whole new level through industry, government, and university collaboration.

The board was recruited from Oracle's most involved customers-those with a history of support for user-centered design activities and with a willingness to work on joint projects with Oracle UX groups. The goal in founding the organization was to identify 10-15 active customers that were enthusiastic about the prospect of a joint venture to improve enterprise software usability. 
The composition of the board is shown in Table 1. Participating on the board were representatives from government, university, and financial, pharmaceutical, and manufacturing industries using Oracle, PeopleSoft, Siebel, and JD Edwards enterprise applications. The distribution of members represented small, medium, and large customer entities across various organization types and user groups. Members were typically chief executives or senior managers with direct accountability within their organizations for user effectiveness, efficiency, and satisfaction with enterprise software. Select independent UX consultants under nondisclosure agreements with Oracle advised and educated the board on an as-needed basis.

Table 1. Oracle Usability Advisory Board Demographics

\begin{tabular}{llllll} 
& Executive & $\begin{array}{l}\text { VP/Dir/ } \\
\text { Chief } \\
\text { IT/ }\end{array}$ & $\begin{array}{l}\text { VP/Dir } \\
\text { Apps }\end{array}$ & $\begin{array}{l}\text { Architect/ } \\
\text { Analyst }\end{array}$ & Other \\
\hline Manufacturing & 1 & 3 & & 1 & 1 \\
$\quad$ Government & 1 & 4 & 1 & 1 & \\
$\begin{array}{l}\text { Education } \\
\begin{array}{l}\text { Pharmaceutical/Medical } \\
\text { Devices }\end{array}\end{array}$ & 2 & 1 & 1 & 2 & \\
$\begin{array}{l}\text { Financial/Insurance/ } \\
\quad \text { Real Estate }\end{array}$ & & 3 & 1 & 1 & \\
$\quad$ Consulting & 3 & 1 & & &
\end{tabular}

Board member organizations were required to:

- sign a Customer Participation Confidentiality Agreement (CPCA),

- attend three working meetings per year,

- perform necessary pre- and post-meeting assignments (typically collecting data within their organizations),

- contribute actively during working meetings and online conferences,

- communicate with and support Oracle usability executives and senior staff driving action items, and

- facilitate Oracle access to users in their organizations for studies that would advance the goals of the group.

Later requirements were to use the Oracle Councils secure Web site for communication and social networking and to attend Web and telephonic conference calls to advance the progress of working groups and to organize activities between meetings.

It was emphasized to new board members that this was a working board. Board members were expected to stay engaged during and between meetings, prepare for meetings, present and advocate for positions representing their organizations, and actively collect and contribute usability information relevant to the board.

As of this writing, the board included 30 representatives from 25 customer organizations, an Oracle chair and cochair, and three Oracle working group facilitators. Recent additions to the board were value-added resellers and database consulting services. 
Two UX consulting firms familiar with the Oracle user-centered design process also sat on the board. A steering committee was formed in 2009 to help lead the board.

\section{How the Board Operated}

Meetings with customers before we had a board typically consisted of a review of customer UX problems with their applications systems. It was often hard to understand and even harder to fix such problems. Enterprise software tends to be highly customized, so we had trouble even recognizing the user interfaces in some cases. Also, customers tended to relegate almost all problems to the category of usability, including integration, installation, performance, and documentation.

The paradigm shift that we were looking for in establishing the board was to engender open sharing, communication, and problem solving at an executive level around topics in enterprise usability that were pertinent to all customers. Organized meetings therefore became a series of dialogues between Oracle and customers and among customers themselves. Presentation of specific screen shots and use cases was encouraged.

Meetings occurred three times in the first year. Meeting themes were determined based on what was of interest to customers, based on their usability issues. Topics for the first year were collaboration tools, business intelligence, and mobile computing applications. Subsequent agendas have been determined in board planning meetings and through online board surveys.

Before meetings were held, board members completed assignments relevant to the meeting that involved reading articles, watching videos, preparing slides, or collecting data within their organizations.

Meetings were rotated geographically to accommodate as many board members as possible. Meeting sites for the first year included the Oracle Conference Center in Redwood Shores, California; the Oracle Usability Labs in Burlington, Massachusetts; and the Oracle Usability Labs in Denver, Colorado. Future meetings may be held at customer sites and in Europe.

Meetings began with an informal dinner hosted by Oracle the evening before a full day agenda. All speakers, facilitators, customers, and lab staff were invited. This helped customers get to know staff throughout Oracle who could serve as future resources. It also allowed catching up between customers, introduction of new board members in an informal setting, and setting the stage for discussion of important topics that would be featured the next day.

Day-long meetings typically consisted of presentations by new members on their top-three usability issues, reports on interim activities and statuses of working group projects, a keynote address on the meeting's major theme by a major Oracle executive, and an afternoon spent in the working groups. These events were followed by new business and a general summary of what happened in the meetings.

The working groups were the heart and soul of the customer board. Groups were originally organized on three key topics, which were based on customer representations of their worst usability problems. The three areas were: user interface consistency and design, integration and performance, and Web 2.0. Customers initially joined a group in which they were most interested, but they could switch groups. New 
board members sampled the discussions of multiple groups. Oracle senior management facilitated the groups. Oracle scribes, often designers and usability engineers, took notes during working group sessions and prepared minutes and action items to be addressed between meetings. Outcomes of these groups were report formats for usability issues, Web conference training on technical topics, and sharing of opinions about the importance of Web 2.0 features.

The issues selected by the working groups were both tactical and strategic. The consistency and design effort was largely based on the desire to provide feedback on current software, pointing out places where a feature was called by two different names or a feature operated differently between application platforms. The Web 2.0 and integration and performance groups were more strategic, generally addressing future users, enterprise software architectures, and functionality.

UX consultants contributed to the working groups in various ways. They generally wore the hats of usability experts but not Oracle experts. Therefore, they were credible to customers for their UX knowledge but not aligned with Oracle in terms of product agenda. They could provide examples from various vendors to illustrate their points and findings from published research on other software platforms.

Between meetings, additional work was scheduled and performed. The primary means of communication was the Oracle Councils secure Web site. This Web site was used by more than 60 Oracle Councils and Customer Advisory Boards to archive and share documents, provide distribution list service, and host polls and surveys. The Web site was not available to the general public, so online communications could be carried out while maintaining confidentiality. The board started out using e-mail, which was too cumbersome and not secure enough for the work that we were trying to accomplish. The polling feature made it easy to take a quick head count on small logistical questions such as potential attendance at a user group meeting or interest in a panel or presentation. Secure online survey tools were also used with the board to collect data.

Working groups conducted conference calls and Web seminars between meetings. Working groups also met in online conferences without Oracle UX facilitation to discuss work between meetings.

More in-depth visits between board organizations and Oracle UX teams were also scheduled between meetings. These meetings typically involved Oracle headquarters lab tours and discussions with customer staff (other than the board members) and Oracle staff selected to represent topics of interest to the customer. These visits took place at the customer sites as well.

\section{What the Board Has Accomplished}

In the first year, there have been three meetings; three Web seminars on secure enterprise search, applications integration, and Web application development tools; a panel at Oracle OpenWorld 2008 (Oracle's annual technical conference and tradeshow); organization of three working groups; and planning of the agenda for the second year of operation.

One working group developed a spreadsheet tool to collect information on usability issues in customer implementations of Oracle software. This spreadsheet was 
designed to give sufficient detail for Oracle developers to address the issues and the working group facilitators to track the issues.

Subtle changes in our relationships with some of our most involved customers resulted. Due to the board meeting exposure, we had greater familiarity with these customers, and we felt more comfortable with each and every encounter. We were able to immediately get down to business and accomplish more work in fewer meetings on customer issues.

As we met these partners at conferences and user group meetings, we continued our agendas and developed new ideas for projects that we could accomplish together. The Oracle UX group met between board meetings with UX groups of board customers to share best practices and concerns.

We have achieved the start of a paradigm shift in the way usability is addressed between customers and the Applications UX department. In general, customers are taking more initiative than they were previously. Some examples:

- Customers have gained a greater understanding of the potential use of the next-generation product. This understanding is a result of communication of features and functions by UX facilitators, Oracle developers, and product managers. We have moved away from selling these customers on new features and functions to customers seeking information.

- Instead of customers providing anecdotal descriptions of their usability issues, there is now a clear process and form to enable Oracle to actually address the problems affecting multiple customers.

- Customers can now participate meaningfully in discussions ranging from UX enhancements in point releases of existing software, to features and functions that need to be developed in future software.

- Presentations of Web 2.0 technology and discussion with customers to overcome unfamiliarity may translate to earlier and greater acceptance of the next release.

- In addition to Oracle UX speakers at industry conferences, board members are now talking to other customers about usability.

- Usability has been promoted from a one-sided vendor initiative to a joint project in which customers can participate.

\section{Future Goals}

The board is now working on a set of customer-driven goals for 2009. These goals include evaluating the efficacy of the inputs that it has made so far on Oracle products. Meetings are planned in conjunction with user groups and hosted by customers. An industry magazine is researching a story about UX with testimonials from board members. Board organizations participate increasingly in customer feedback sessions on pre-released products at industry conferences.

Beyond 2009, the board may sponsor projects such as participating in beta-style product trials at customer sites, inviting vendors to participate in themed meetings, and hosting a usability conference. 


\section{Conclusions}

The success of the Oracle Usability Advisory Board resulted from having faith in customers as equal partners in the effort to improve enterprise software usability. The customers have come through with virtually everything that we expected of them and more. These were our most involved customers, who became even more interested and active as they spent time and effort with us on joint projects.

Some lessons learned:

- Customers appreciate rotating meetings to different geographical sites because it minimizes travel expenses. Rotation also enables a variety of local labs and technical talent to host and participate in meetings with lower cost and effort.

- The board needs a quorum of active customers in good standing for its opinions to convince Oracle development. UX needs to be able to "name names" when providing feedback to development and marketing. Chief executive opinions are particularly valuable.

- Customers are willing to pay their own expenses and spend time and effort to help vendors achieve the next level of usability. They are also willing to read articles and take online training to help themselves understand the latest trends in technology and usability.

- To conduct successful working groups, there must be a core set of customers who are willing to work on a project until it is done.

- It is helpful to have customers on the board who like to present to others. "Customers talking to customers" was a particularly compelling model in convincing audiences of the importance of usability.

\section{References}

1. Detweiler, M.: Managing UCD with Agile Projects. interactions 14(3), 40-42 (2007)

2. Lee, W.O., Solorzano, S., Harrison, C.: Creating and Managing User Partnership Programs. In: Proc.CHI 2005, p. 2123. ACM Press, New York (2005) 